\title{
Carlos Reyles
}

\author{
$(1868-1938)$
}

Del Uruguay, tierra de gauchos, de grandes poetas y de radicales impulsos sociológicos, viene este gran novelista. E1 Uruguay es un patio pequeñito, de fresco color celeste, en este espacio que es América. País nuevo y curioso, tiene esa inquietud de los que están dispuestos a la belleza. Un canto ancho de promesas mira por la ventana azul de este país fragante aún de la infancia. (I) Allá, en Montevideo, azotada eternamente por su mar, bajo la mirada serena de su cerro, dormida bajo un cielo suave, vive Carlos Reyles, en una alegre casa, que fuera de campo si no estuviera en la misma capital. Allí le conocí una tarde de abril de mil novecientos treinta y tres, y mientras charlábamos se recortaba en la ventana de su cuarto de convaleciente, un dulce cielo cortado a veces por acrobacias de gaviotas. Alamos y sauces temblaban en el horizonte pequeño, y por el jardín pasabà un rumor de viento de mar.

A los sesenta y tantos años es Reyles todavía hombre joven, por la insólita energía de su vida interior. Queda todavía mucho en él de aquel garboso señor pintado por Zuloaga, de cuerpo

(1).-Juan M. Filartigas, Mapa de la poesía, 1930. 
entero y de frac, mezcla curiosa de sajón y andaluz. La gran movilidad de sus gestos denuncia al recio polemista, al batallador de la idea, y el movimiento aparatoso de sus brazos y. la cálida voz llena de masculinas sugérencias nos hacen sentirnos en presencia de un matador ya retirado del redonclel. El rostro es seco, huesudo, delgado; la nariz afilada, los ojos pequeños, las cejas pobladas, el pelo gris y escaso. Las cien arrugas que le cruzan la cara saltan en todas direcciones cuando habla, y le dan un aire simpatiquísimo de gitano que ha vivido muchos años en París. Se siente en su palabra al hombre autoritario y dominador, dominado empero por su gran cultura y por su fina sensibilidad. Sus ideas se suceden rapidísimas, como destellos de floretes, y luego sus silencios breves anticipan ya en el brillo de sus ojos las nuevas palabras. Es un conversador agradable, un tanto abrupto; un espontáneo de extremada agilidad mental, que va dejando caer opiniones sin repetirse, en el dionisíaco placer de su expresión.

Crispo Acosta nos da una descripción de un Reyles más joven :

“Tienen su fisonomía y su temperamento mucho de español y de andaluz; une su figura al empaque señorial, cierto garbo de majo; el cuerpo chico y ágil, ancho de espaldas, parece por su movilidad nerviosa, hecho con rabos de lagartijas, según la expresión que él mismo aplica a uno de sus personajes; una osatura fina se marca reciamente a flor de piel, en los pómulos, en el caballete de la nariz, a los lados de la mandíbula inferior, en el mentón hundido al medio, en el cránco descarnado, voluntarioso, bajo de frente, de sienes amplias y nuca alta; los ojos, vivos como dos gotas de acero, en cuencas hondas y grandes, miran con dureza bajo el arco firme de las cejas hoscas; con frecuencia un gesto de altivez, una sonrisa despectiva, comprime sus labios delgados sobre la doble hilera blanca de sus dientes iguales y menudos; la nariz es fuerte como una afirmación terminante. Debe dar a quien no lo conoce, la inpresión áspera, violenta, casi provocativa, de un espíritu vehemente, de sentimientos secos, movido por el deseo de imponer 
su orgullo a la consideración humillada o al odio -todo menos la indiferencia - de los circunstantes". (I) .

Reyles nació en Montevideo, de padres uruguayos; se educó en el colegio Hispanouruguayo; allí estuvo varios años hasta que su padre le llevó a vivir a su lado. Su-interés por la literatura data de sus días de escuela; en un concurso literario sostenido cuando sólo tenía diez años de edad, se sacó como premio una colección de la Biblioteca de autores españoles. Se interesaba, sobre todo, por la novela y en un ensayo infantil trató de resucitar el género picaresco. Sin embargo, hasta sus catorce años la mayor parte de sus trabajos fueron escritos en verso.

E1 padre de Reyles era rico terrateniente, que a veces se tornaba político, siendo varias veces senador. Hombre práctico y moderno, supo aplicar los adelantos de la ciencia en sus haciendas, logrando una enorme fortuna. Cuando murió, en I886, dejó su dinero y sus tierras a su hijo. Millonario a los dieciocho. años, el joven Reyles contrajo matrimonio y se dedicó a aumentar su ya respetable cultura literaria. En I888 publicó su primera novela, Por la vida, audaz ataque contra la sociedad y la familia. Al quedar huérfano, Reyles comenzó una lucha brutal en contra de sus albaceas, y esta protesta determina esa novela. Por la vida es la historia de Damián Casariego, huérfano de madre e hijo único, que estudia en una escuela de Montevideo. El joven tiene que luchar en contra de sus parientes que desean apoderarse del dinero del padre. Luego pasa por períodos de desesperación, cae en el vicio vulgar, propio de los jóvenes de su edad en su país, y por fin contrae matrimonio con una joven de humilde origen. El espíritu pesimista de la obra no está en armonía con la juventud del autor, aunque sí con ciertos estados psicológicos de aquellos años de su vida. Muchos de los datos internos de la novela se podrían utilizar para reconstruir la vida de este escritor, aunque, claro está, la novela no es completamente autobiográfica.

(1) - "Lauxar", Carlos Royles, págs. 10 y II. 
En I892 hace Reyles su primer viaje por Europa. Visita Francia, Inglaterra y España y se detiene por algún tiempo en Sevilla. Allí hace amistad con algunos periodistas y publica en El Posibilista, de Sevilla, su cuento Doménico. Ese mismo año publicó algún otro ensayo en un periódico madrileño. Vuelto a su país natal, se dedicó a la ganadería y a la agricultura, sin descuidar un solo momento sus empresas literarias. $\mathrm{Su}$ vida ha sido un alto ejemplo de plenitud y fuerza. Ha tenido sonados triunfos y rotundos fracasos; pero siempre su fe en el ideal le ha salvado. Ultimamente, a raíz de la pérdida de su extraordinaria fortuna, el gobierno de su país le ha honrado con un puesto de conferenciante en la Universidad de Montevideo.

Reyles ha tenido siempre un concepto trascendental de la novela. Después de la publicación de El extraño, y sobre todo, a causa de las opiniones expuestas en el prólogo de esta narración, don Juan Valera criticó injustamente al escritor uruguayo. El autor de Pepita Iiménez había hecho el elogio de Primitivo en el Correo Español de Buenos Aires, pero poco después, en El Liberal de Madrid, interviene su espanolismo agudo en su concepto de crítica literaria y así dice:

"Su extravío proviene de la ya mencionada enfermedad epidémica, nacida del menosprecio con que miramos a nuestra nación o a nuestra raza, y que se nota, por fortuna, más que en España, entre los escritores hispanoamericanos. Consiste la enfermedad en cierto candoroso y desaforado entusiasmo por la última moda de París en literatura, como si en la literatura estuviesen bien las modas, y como si en literatura se fuese progresando siempre, como se progresa en cirugía o en química y mecánica aplicadas a la industria”.

Naturalmente que Valera llevaba la parte más ingrata de la polémica, y bastaron unos cuantos argumentos de Reyles, para que la mayor parte de los escritores españoles se pusieran de su lado, En el mismo Liberal de Madrid publicó Reyles su 
contestación, que tituló La novela del porvenir. A vuelta de otras razones escribía:

"Hasta cierto punto cabe negar que en lo puramente literario y artístico no existe progreso, o mejor aún, que el progreso no es continuo e indefinido. Un arte o género literario PROGRESA mientras duran las especialísimas causas y condiciones que lo inspiran y sustentan, llega al apogeo y nace la más bella flor; luego caen las hojas, brotan otras nuevas y a poco el árbol viste nuevos ramos".

En, esta polémica intervinieron Emilia Pardo Bazán, Leopoldo Alas y por fin Gómez de Baquero, y éste último dió toda la razón a Carlos Reyles. De esta manera, Valera y Reyles contribuyeron con un nuevo capítulo a esa obra interminable que las generaciones vienen escribiendo y que se llama: la batalla entre los antiguos y los modernos.

Reyles escribe por una necesidad imperiosa; no tiene lo que se llama vulgarmente una pluma fácil, antes por el contrario, elabora con paciencia y espacio y después de terminada la obra vuelve a corregirla, quitando los trucos y los efectismos. Trabaja con devoción y cariño su obra, y aunque conoce muy bien sus clásicos castellanos, está muy lejos de ser purista. E1 escritor - y éstas son frases suyas- vive en medio de las impurezas de la vida y en ella trabaja y debe decir las cosas tal como las piensa.

Aunque no es un realista en el sentido común de la palabra (si alguna vez le hemos considerado como tal, ha sido sólo desde un punto de vista técnico), Reyles parte de hechos reales en todas sus novelas y luego, lanzado ya en el proceso estético, se aparta de ellos y deja rienda suelta a su fantasía. Su método arquitectónico no es nuevo, pero sí raro en nuestra raza de escritores repentistas: Reyles hace primero el esquema de su novela en un rápido y breve desarrollo de situaciones; de este modo le resulta el cuento, y más tarde, después de haber elaborado largamente el problema sociológico o psicológico que quiere presentar, se lanza de lleno al relato largo y sostenido. Es así como a cada una de sus novelas corresponde un cuento, en esta forma: 
El extraño - Raza de Cain.

Primitivo - El terruño.

Capricho de Goya - El embrujo de Sevilla.

Mansilla y el pial - El gancho Florido.

Una mijer pasó - 1 batallas de amor, campo de pluma.

A Reyles le interesan profundamente la sociología y la filosofía, y de aquí provienen los continuos apartes de sus novelas; de sus tipos, más que la vida exacta, le interesan las posibilidades de su realidad. A veces la psicología de sus caracteres es un tanto arbitraria y el autor así lo comprende y lo explica diciendo que la razón estética es superior a todo:

"Lo esencial no es que el narrador nos presente escenas y tipos reales en sí, sino que intensamente y subjetivamente lo parezcan. Lo irreal suele ser muy a menudo verosímil en el mundo mágico de la creación literaria ; del mismo modo que lo arbitrario, lo estrambótico y hasta lo horrible reales se trasmutan, por misteriosa alquimia, en inmaculada belleza, en el plano del arte, si están con arte representados". (I)

De acuerdo con las ideas de Reyles, si el autor sigue esta voz interior de predominio estético, tiene que triunfar. Por fin, llegando a una concepción estrictamente subjetiva del arte de la novela, a veces en pugna con lo que él mismo ha hecho, Reyles cree que todo autor tiene sólo un libro y que lo demás es extraño a su idiosincrasia.

Reyles es, como hombre y como escritor, un cosmopolita; es en la prosa un verdadero modernista, como lo fueron José Enrique Rodó y Díaz Rodríguez. De España toma la lengua una especie de casticismo sacudido por la vibración de su temperamento, un casticismo medular que en su forma externa no lo es, porque Reyles se permite el galicismo, el vocablo plebeyo y el americanismo. Dificulto que otro escritor pudiera haber escrito un libro con más sabor racial que El embrujo de

(1) - - El nuevo sentido de la narración gauchesca, Montevideo, I930, págs. 7 y 8 . 
Sevilla, y sin embargo, cualquier Zoilo puede encontrar en esta novela mil razones para asegurar que no es un libro castizo. Del francés ha tomado este uruguayo la técnica y a veces los asuntos; la universalidad de sus temas le da un aspecto eminentemente europeo a toda su labor, europeo antiespañol, si se me permite la expresión. Si alguna vez se ve en su estilo o en su manera de construir algún rasgo de Gracián, Góngora, Valera, Pereda o Galdós, es mucho más frecuente encontrarle afinidades con Huysmans, Barrès, Zola, Anatole France, Oscar Wilde, Dostoiewski.

El consenso de la crítica reconoce en La raza de Cain su mejor novela, pero Reyles, consecuente con su manera de entender la vida y sus problemas, declara que su obra dilecta es El embruio de Sevilla.

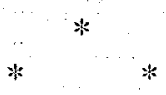

Beba, terminada en octubre de 1894 , es la primera novela de aliento de Reyles; Un breve resumen de la obra nos permitirá analizarla mejor. Cuando Isabel se casa con Rafael Benavente, Gustavo Ribero, su tío, para olvidar su tristeza y su abandono, se dedica a hacer grandes reformas en su hacienda. Después de una ausencia de dos años vuelve Beba de visita acompañada de su marido y de la familia Benavente. Cansada de la vida frívola e insípida de la ciudad y desencantada demasiado pronto de su marido, un elegante $\sin$ ideales, Beba se halla feliz en la casa en que nació y al lado del tío cariñoso, inteligente y activo. Por el contrario, sus suegros y su marido están cada día más molestos y piensan con temor que Ribero, al comprometer su propia fortuna en los enormes gastos que hace para mejorar sus casas y su ganado, pone también en peligro la parte que corresponde a Beba, y por lo tanto a ellos. Empiezan a oponerle sorda resistencia. Como tío y scbrina están juntos la mayor parte del tiempo en sus trabajos campestres, Rafael empieza a tener celos de Ribero y a sentir odio por su mujer, hasta que llega un momento en que no puede soportar más y decide volverse a Montevideo. Con las grandes lluvias 
ha crecido mucho el Río Negro, que los viajeros tienen que cruzar, pero Rafael no hace caso a los consejos del resto de la familia y todos emprenden el viaje en algunos botes; en medio del río la canoa en que va Beba es arrebatada por la corriente y arrastrada río abajo. Ante la impotencia de todos, sólo Ribero tiene el valor de arrojarse al agua y logra trenarse al bote, que salta sobre la corriente amenazando hundirse a cada momento. Día y noche sigue creciendo el río. Ante la muerte próxima Ribero se atreve a confesar su gran amor a Beba. Se salvan, sin embargo, y en una lejana choza del bosque se aman $\mathrm{y}$ son felices. Pero al fin tienen que volver a la estancia y encuentran allí a Rafael. Beba confiesa a su marido su amor por Ribero, y Rafael parte angustiado mientras ella, triunfante, dice a su tío: "-Ya puedo ser tuya por entero: nada se opone a nuestro amor". Desde ese instante Ribero empieza a sentir el remordimiento de su acción. Rafael sufre, más que por la pérdida de su esposa, por su temor al ridículo, al "qué dirán", pero al fin, a medias consolado, parte a Europa. En casa do Ribero las cosas van de mal en peor; a la breve felicidad del gran amor sigue el remordimiento del tío; los negocios se echan a perder; hay que seguir hipotecando las propiedades. Ribero empieza a dudar de la eficacia de sus reformas y se torna huraño. Los potros de raza, que eran orgullo del hacendado, heredan, por ser hijos de hermanos, las enfermedades de los padres. Lo que él cree su gran pecado cuelga como una espada sobre todos los actos de su vida y en una ocasión, enloquecido de ira, da de puñaladas a su potro favorito. Para rehacer parte de su fortuna Ribero parte a Europa con una buena cantidad de caballos finos y Beba se establece por unos meses en Montevideo. La alegría de stu embarazo la hace olvidar la ausencia de su amante. El golpe final de su tragedia lo recibe con el nacimiento del hijo, un verdadero monstruo en cuya horrible cara se confundían los ojos, la boca y la nariz; afortunadamente el niño nace muerto. Beba soporta algunos días su tragedia, pero cuando recibe una carta bastante fría de Ribero, decide terminarlo todo $\mathrm{y}$ se sticida, arrojándose al mar.

Beba no es una novela de estética pura, sino una obra de 
propaganda económico-social. Aunque Beba es la protagonista, el personaje principal es Tito Ribero, personaje nietzscheano que lucha por establecer en el Uruguay la ganadería en forma moderna, científica, y es criticado por los campesinos que se aferran a los métodos primitivos de crianza. La estancia de Tito no es el pago semibárbaro que describen Acevecio Diaz y Viana, sino el establecimiento de tipo inglés, con potros de pura sangre y toros Durham. Beba es una señorita romántica que lee a Bécquer y a Musset, representa Romeo and Juliet y sueña con un novio ideal. Se siente heroína de tragedia y se mira al espejo para ver si su mirada es triste como la de Ofelia. Cuando sabe que es "hija del amor" se torna más romántica, goza al llorar sin motivo y hace esfuerzos para llorar más; su gran deseo es amar hasta morir; hace versos y escribe su diario íntimo. Siempre soñó que su casamiento iba a ser un extraordinario suceso y en la realidad sólo fué una cosa cualquiera e insignificante. Su carácter independiente y rebelde se explica por su niñez montaraz. Beba tiene sus puntos admirables -independencia de criterio, idealismo, espíritu de empresa- y grandes flaquezas que a veces tocan en lo ridículo; en su noche de bodas se desilusiona porque su marido entra en la alcoba en paños menores, y cuando se cree burlada, vencida, destrozada para siempre, hay que acusarla a ella y no a él, a su sentimentalismo estúpido y morboso. En su concepción de lo que debería haber sido su alcoba de casada se demuestra su cursilería enfermiza:

"Nada había allí de lo que yo habría deseado para mi dormitorio de casada: jah, y qué bien me lo tenía construído en un rinconcito de la imaginación! Estaría tapizado de raso blanco; la cama había de ser de madera primorosamente labrada, con ángeles en relieve o alegorías de amor; los cortinajes grises para que el lecho estuviera así como a la sombra, y las sábanas azules, sobre las cuales parecería la carne de mi cuerpo una nube rosada. Una alfombra de plumas cubriría el suelo, aromas orientales embalsamarían el ambiente, $y$ por todas partes se verían regaladas poltronas, blandos divanes y preciosas pie- 
les. En un nido así, viviríamos amándonos mucho el hombre rubio y yo". (I)

Por lo que al dormitorio se refiere y aunque fuera regalo del suegro, muy fácil habría sido para el marido sustituirlo por otro más de acuerdo con los gustos voluptuosos de la esposa, pero lo que sobrepasa toda imaginación es eso del hombre rubio porque si así le quería así debió escogerle, y no moreno. iQué de tragedias no liabría si todas las señoritas siguieran igual conducta en las noches nupciales!

Ideales encontrados batallan en esta obra; por un lado el autor ataca la educación pedante y hueca de los colegios, el estado de corrupción de la sociedad de Montevideo y aboga por la dignificación de la mujer. Por otro, el sentimentalismo agudo y la educación moral descuidada de Beba hacen que se entregue al primer hombre elegante que encuentra en su camino. Su casamiento indica una falta absoluta de reflexión, de madurez, y la facilidad con que Ribero permite el matrimonio no se alcanza a justificar con su delicadeza de miras en el asunto. Mucho más habría luchado por conservar un potro fino que por mantener a su lado a esa sobrina, a la cual idolatra. . La psicología de Ribero no nos convence. El hombre fuerte resulta inferior a la mujer, pues mientras Beba acepta con orgullo su vida de concubinato, él, logrado ya su gran amor, tiene escrúpulos de seminarista. Su remordimiento es indigno del hombre que aparece en las primeras páginas de la novela, y cuando la ruina económica le alcanza, el nietzscheano culpa de su desgracia a la mujer que lo ha sacrificado todo en su provecho.

Beba es una curiosa mezcla de realismo y de romanticismo. Reyles, que ya conoce a Zolá, se documenta con gran cuidado para exponer sus opiniones sobre la industria ganadera. Hay páginas enteras más propias de un tratado técnico sobre la materia que de una obra estética. El campo está descrito con seguridad y sin exageración; los campesinos casi siempre están

(i).-Beba, pág. 269 
bien observados; la descripción del paisaje tiene una profunda belleza, pero en lo que toca al conflicto sentimental, el método cambia, y nos creeríamos en presencia de una nueva María, hecha con el mismo entusiasmo lírico de Isaacs y con todo su romántico empaque.

No estamos de acuerdo con Alberto Zum Felde en que Beba sea superior a La raza de Caín y El terruño. En Beba hay cierto prurito por hacer algo trascendental, pero Reyles no alcanza el logro de su ambición, y en vez de hacer obra puramente literaria le resulta una especie de tratado de economía rural. E1 romance pasional se nos antoja superpuesto, ajeno casi al motivo inicial de la novela, cual es la crianza y exportación de ganado.

Hay algunos defectos más pequeños que no hemos visto apuntados antes. Al principio del libro, al defender el cruzamiento de consanguíneos, Ribero menciona sólo las superioridades de los padrillos y cuando al fin del libro aparecen los potros enfermos, se da cuenta de que han aparecido males hereditarios a causa del apareamiento entre hermanos. Hay que pensar que sus conocimientos son bastante incompletos o que así lo quiso Reyles, sólo para hacer novela. Nos parece perfectamente ridículo que Beba se dedique a leer obras pedagógicas de Spencer, Froebel, Sheldon y Wickerslan, porque va a tener un hijo; sería más justo que se hubiera dedicado a hacer caminatas, a cuidar su alimentación y a coser los vestidos de la criatura. Hasta en esto está presente la sombra de Zolá. Algunas veces el estilo es excesivamente literario en circunstancias en que sería de rigor una perfecta sencillez, llegando a veces a una verdadera aberración, v.g., cuando Beba y Ribero son arrastrados por la corriente, a lo que ellos creen una muerte segura, él exclama:

“ ¿No ves a la vieja e inexorable Parca?", palabras que sonarían mejor en un clrama romántico que en una novela realista.

E1 final de Beba no es, como dice Zunn Felde, un éxito del artista sobre el propagandista, ( I) al contrario, estamos de 267.

(I).-A. Zum Felde, Proceso intelectual del Uruguay, Tomo II, jág. 
acuerdo con "Lauxar", cuando dice: "la impresión que se recoge en $B e b a$ no es bien clara, completamente nítida". ( I)

La novela desenvuelve el símbolo hasta el fin y así nace a Beba un hijo monstruoso, como fueron anormales los potros, hijos de consanguíneos. Del mismo modo, la muerte de la heroína indica una pena, pero caprichosamente impuesta, porque Beba sólo merecía la felicidad después de haber tenido el valor de desafiar las convenciones sociales para vivir libremente con su tío. Si el pago de su independencia y de su desinterés es la desesperación, Reyles ha cometido una gran injusticia. No queremos creer que el autor haya castigado a su protagonista por no haber aceptado su destino al lado de un hombre vulgar. La única solución sería considerar a Beba como víctima de una sociedad cobarde e hipócrita, pero es difícil creer que Ribero haya sido el instrumento de esa venganza. Lo más probable es, sin embargo, que Reyles, demasiado influido por Ibsen y Zola, haya considerado las leyes de la herencia superiores a esa armonía moral que debe existir en toda obra literaria. Por otro lado, un desenlace optimista se imponía. De ese modo Ribero habría ganado su batalla contra la rutina y la pereza y Beba la suya contra la mojigatería y los intetereses creados. La solución optimista habría sido más verosímil, si menos dramática.

El programa ideológico y estético de $R a s a$ de Cain estaba ya anunciado en El extraño, su segunda Academia. En El extraño, Julio Guzmán es un sentimental neurótico que se encuentra mal hasta en el seno de su propia familia. Es definido así por Reyles: "Julio Guzmán, había viajado, leído bastar1te $y$ vivido aprisa. Tenía la sensibilidad muy afinada y el gusto pelilloso y exigente. Su inteligencia era aristocrática, su modo natural, ser complicado: Amaba lo raro, lo difícil. En Europa hubiera sido un artífice primoroso... En América se dedicaba a coleccionar valiosas pipas y libros. En Uruguay no encontró con quien hablar de sus aficiones favoritas. Le oían como quien oye llover. Replegóse sobre sí y su egoísmo

(1).--Lauxar", Carlos Reyles, pág. 4r. 
tuvo un verdadero y espléndido florecimiento. Leía sin descanso, cultivaba a veces la música, el dibujo, la pintura, hacía versos. Mientras la multitud se agitaba en las faenas cotidianas él exclamaba: Es necesario libertarse". (I)

Enamorado de Sara Casares y ante la amenaza del esposo de ésta de llevársela a Europa, le sugiere, ya apoderado de su voluntad, que ella exprese el engaño madurado por él, su falso amor por la hija de Casares, Cora. Así podrán estar siempre juntos. Pero he aquí que Guzmán se prenda verdaderamente de la joven y en un momento de sinceridad le revela la traición. Sara, que está en el aposento inmediato, oye las declaraciones y cae desmayada. Guzmán pierde así el amor de las dos mujeres. Abandonado y solo, llega a la conclusión de que sus versos no son nada, que lo intelectual es estéril, que su existencia no tiene objeto y que sólo el amor y el dolor son fecundos.

Alrededor de este tema construye más tarde su Raza de Caín. Aparece otra vez Julio Guzmán, casado con Amelia, hija del rico estanciero Crooker. Es el mismo personaje de El extraño: "leyendo y viajando habíase dado Guzmán una cultura variadísima, que lo refina más de la cuenta, hasta el extremo de convertirlo en un ser exótico y en una preciosura de la sensibilidad humana muy curiosa, pero sin aplicación posible en un medio de pura actividad comercial, hostil a las blanduras y afeminamicntos de las civilizaciones muy adelantadas. Los delicados gustos adquiridos en el extranjero, no lo dejaban encajar debidamente en la sociedad en que vivía; en todas partes sentía esa sorda irritación que se experimenta delante de las personas que consideramos diferentes y por lo tanto enemigas; y las continuas rozaduras y desagrados lo indujeron a replegarse sobre sí y a robustecer su egoísmo. Las mañas y aficiones del coleccionista de estampas y camafeos, degeneraron en curiosidad psicológica, y fué Guzmán lo que llamaría el sutil e impertinente Barrès, un amateur d'ames, un observador implacable de las propias y de las ajenas sensa-

(1) --Raza de Cain, págs. $35,36$. 
ciones, que luego, fatalmente, dió origen al irónico, al escéptico, a la criatura falta de energía para la acción en que a la postre vino a convertirse". (I)

No son felices los esposos. Al exaltado y vago idealismo de Guzmán se opone el bien cimentado sentido común de la esposa; de este modo, cuando él cree haber hallado una solución a su falta de energía con su plan de publicar una revista cultural ilustrada, su mujer se niega a facilitarle dinero, lo que es para el sensitivo soñador un golpe terrible. Distanciado de su esposa, encuentra consuelo en Sara, aquella misma amante de $E l$ extraño que, viuda, por los pesares que causara al marido su infidelidad y todavía sangrante la herida que le infiriera Julio, al revelar a Cora el tremendo engaño, le perdona todo y vuelve a ser para él hermana, madre y mujer. Para eternizar el amor, como para demostrarse capaz de la volición viril, obsesión de los abúlicos, Guzmán hipnotiza a Sara y la hace desear la muerte. Hecho el pacto de suicidio, Julio mata a Sara y cuando quiere quitarse su propia vida comprende el abismo que hay entre la idea y el acto, y le faltan las futerzas para cumplir su intento. Pero ésta es más o menos la intriga de El extraño y naturalmente en La raza de Cain tiene Reyles que introducir nuevos personajes y nuevas situaciones dramáticas. Lo que Reyles hà hecho es agregar dos nuevas novelas cortas. 'La más importante describe el carácter y la vida de Jacinto Cacio, individto de baja alcurnia que quiere ponerse a la altura de sus protectores, los Crooker. Cacio es un temperamento sensible, analítico; intelectualmente anarquizado y roído por los celos y la envidia; como Guzmán, es un enfermo de la voluntad. Enamorado de Laura, novia de Arturo Crooker, usa de todos los medios para quitárselá al joven fuerte y optimista, pero fracasa y se pone en ridículo. Cacio cae bajo la influencia del pensamiento disolvente de Guzmán, quien le hace concebir el crimen como único medio de poner en evidencia la voluntad. Aunque las teorías de Guzmán son siempre abstractas, Cacio decide asesinar a Laura para vivir con ella eternamente en zonas ideales,

$$
\text { (1) - El extraño, capitulo V. }
$$


y la víspera de la boda, la envenena. La tercera novela nos relata la vida del señor Menchaca y de Ana, su esposa. Pequeño comerciante de provincia, Menchaca comete el error de casarse con una mujer bellísima, mucho menor que él, coqueta y pretenciosa. Cuando les conocemos, Ana engaña a su marido con Arturo Crooker. Más tarde, y ya en Montevideo, Ana se asocia con unos cómicos y por fin abandona a Menchaca $y$ se va con los actores a Europa. Lo patético de la narración es el amor profundo de Menchaca por su mujer, amor que le hace soportar todo, hasta el engaño y que se satisface con tener cerca a la mujer adorada. Con el abandono de Ana cae Menchaca en la degeneración, pérdida de la voluntad, alcoholismo, locura.

La raza de Caín es la más psicológica de las novelas de Reyles. En Beba y en Primitivo hay mucho de la vida del campo uruguayo y en El embrujo de Sevilla lo más importante es la ciudad, en su vida pasada y presente; en La raza de Caín pueblo y ciudad se esfuman y sólo se destacan los personajes, con sus inquietudes y sus pasiones. La técnica es puramente europea pero aplicada con cordura y en un ambiente propio. Reyles se sabe al dedillo sus novelistas europeos del siglo pasado, en especial los franceses. De Tolstoy tiene la fe en la bondad de la vida campestre; de Flaubert hay reminiscencias (Guznán recuerda al Frederick de L'éducation sentimentale y a Mme. Bovary) (I). De Zola posee el culto por la información documentada y la preocupación por las leyes de la herencia y del medio. De Stendhal, Bourget y Prévost, la maestría en el análisis psicológico. Ventura García Calderón reconoce esta deuda del escritor uruguayo cuando escribe:

"Es balzaciano Cacio, un Rastignac de corto vuelo; es danunciano Menchaca, un triste Epíscopo. Son rusas, es decir adnirablemente bárbaras, tienen el júbilo sombrío que hiela en Dostoyevski, la ardiente y lúcida preparación del envenenamiento de Laura, las escenas en donde Guzmán y su mujer, Cacio

(1)-Ta influencia de Mme. Bovary es nucho más evidente en Beba. 
y su hermana se aborrecen; en donde Menchaca se arrodilla gimiendo ante la mujer que lo deja y lo envilece. En fin, arremolina las últimas páginas del suicidio frustrado, el turbio frenesí del Triunfo de la Muerte". (I)

La influencia de Huysmans es evidente en La raza de Caín. Como Joris-Karl siente Julio Guzmán la obsesión de todas las bajezas morales, de la fealdad y la corrupción. La futilidad de todos los esfuerzos humanos le desespera y busca la evasión en la metafísica, en una vida de refinamientos extraños, en una creencia religiosa o en el suicidio. Julio, como Des Fsseintes en $A u$ rebours, enferma y enloquece, busca consuelo en poetas mórbidos como Carlos Baudelaire y por fin trata de suicidarse. Las siguientes líneas $\tan$ bien pueden referirse a Julio Guzmán como al Conde Montesquieu Fézénsac:

"Cerca de la mecedora, en un par de estantes de sándalo adosados al muro y tallados por Guzmán, tenía éste sus pipas y sus autores predilectos, que él mismo había encuadernado de un modo caprichoso, según el espíritu de la obra. Las flores del mal de Baudelaire, su poeta favorito, lucían una cubierta de pergamino sobre cuyo color, grato al ojo, de marfil viejo, ostentaban sus tintas inquietantes, ora calientes como una gota de sangre, ora lívidas y cadavéricas, el lotus, los asfodelos, las mandrágoras, las adormideras, y otras de esas flores extrañas que turban el ánimo como una mirada de mujer. En el medio, en oro mate, reposaba en la actitud de una esfinge, el gato que obsedía al poeta maldito". (2)

Se ha dicho que Raza de Caín es la mejor novela de Reyles. Es probable. E1 análisis de las almas de Cacio y de Guzmán es detalladísimo y le descomposición de estos caracteres tiene positiva grandeza. La mayor parte de los críticos - Don Juan Valera entre otros (3) -, criticaron a Reyles su admiración por el Guzmán de $E l$ extraño; pero el novelista de Raza de Cain entiende las cosas de otro modo ahora y condena al so-

(1).-S.emblanzas de América, págs. 170, I7I.

(2).-La raza de Caín, seg. ed., pág. 213.

(3).-Véase Juan Valera, Cartas americanas, T. III. 
ñador neurótico a una vulgar cárcel. El nihilismo moral de las Academias da paso a un realismo de buena ley y tanto Cacio como Guzmán sólo merecen el desprecio del lector; por otro lado ya Reyles se inclina mucho más al culto de la fuerza y del dinero como elementos constituyentes de una vida sana y feliz. Crooker y su hijo Arturo son los fuertes, los que triunfan en todo, los hombres sin veneno y sin malicia. Adivinamos que si hay algo de Reyles en el Julio de El extraño ahora el autor ha querido ver su imagen en Arturo y no en Guzmán. El carácter de Cacio degenera a veces en caricatura, sobre todo cuando adula sin necesidad y hasta la vergiienza. Las mujeres en general están bien presentadas con excepción hecha de Sara, figura literaria más que mujer de carne y hueso. Las escenas entre Menchaca y su mujer son a veces de una sublime ridiculez y otras de un dramatismo estupendo y en esta parte de la novela se podrían desgajar las páginas más intensas de toda su labor.

El ponderado crítico "Lauxar" (I) fija con seguridad la evolución crítica de Reyles, desde Beba hasta El terruño, en tres fases sucesivas:

I.-Por la vida y Beba, momento de arrebato en que Reyles va contra todo lo humano.

2.-Las Academias, momento de voluptuosidad en que el refinamiento en el arte se convierte en el fin último y supremo del espíritu y la civilización.

3.-Raza de Caín, El terruño, momento de reacción en contra del individualismo indisciplinado y del sensualismo puro $(R a-$ sa de Cain) y fe en la acción y en la voluntad (Muerte del cisne y El terruño).

Quiere arrasarlo todo en el mundo cuando empieza a escribir, dice "Lauxar". En seguida, con desprecio de todo, se vuelve al goce perverso de la artificialidad cultivada, y acaba por último, de acuerdo con el sentido comín de la buena gente, por aceptar la realidad como ella es, sin omitir que dentro de ella la voluntad humana es, en lo htmano, una fuerza de primer

(1).--'Lauxar", Carlos Reyles, Montevideo, I9ı, pág. 26. 
orden. Paralela evolución experimentaría su estilo, según el crítico uruguayo: En Beba sólo se atiene, como calidad estilística, al fraseo de corte castellano; en las Academias hace uso de la escritura artística de origen francés; en La raza de Caín y El terruño, la sensibilidad cede a la fuerza. Todo esto equivale a decir que después de un tanteo de ensayo creador espontáneo y primitivo pasa por un período de imitación y encuentra su camino de Damasco y su verdad - realismo y violencia de expresión- en sus dos últimas novelas.

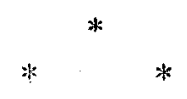

El título del libro es anuncio de su contenido. Terruño, es decir, novela de la tierra uruguaya, que es la de su autor. Mas, he aquí que no encontramos una minuciosa descripción de ríos, montes, llanuras, sino un paisaje limitado a los alrededores de las casas de los patrones, con sus corrales, potreros, lecherías, y un grupo églógico de ovejas, encanto de los ojos y de las manos femeninas. $Y$ es que verdaderamente $E l$ terruño no es la obra bravía que el lector extranjero espera de estos países nuestros en los cuales parece que fuera de obligación comentar lo grandioso y slo exótico. Y sin embargo, estamos en presencia del campo uruguayo, pero de un campo cercano a la ciudad y tocado ya de civilización. Al lado de la pulpería hay granjas, queserías, gallineros modernos, ovejas finas y toros Durham. El producto de la lana y la leche se cambia en la ciudad por jofainas, peines, zapatos y hasta objetos de lujo. En este campo sitúa Reyles sus personajes que son, por orden de importancia en la novela: Mamagela, Primitivo, Tocles, y Pantaleón. Mamagela es una vieja simpatiquísima, refranera y de sólido sentido común, dueña de la pulpería del lugar. Sus dos hijas, Amabí y Celedonia, son las esposas de Tocles y Primitivo, respectivamente. Primitivo es un gaucho bueno y sano de alma, dedicado al cultivo de su suelo y a la crianza de ovejas. Es feliz y sólo piensa en el ahorro para aumentar sus propiedades. Pero un día la tragedia entra como huracán en sa casa, en la 
persona de su hermano de madre, Jaime, que alevosamente le seduce a su mujer y le marca el rostro (a Primitivo) con una tremenda puñalada. Primitivo se abandona a la embriaguez y al ocio y cae en la degeneración y en la locura. Aprovecha la lucha de los partidos políticos, se une al colorado con el único deseo de vengarse de su hermano que pertenece al blanco. Un día se encuentran los hermanos en el campo de batalla y Primitivo degüella a Jaime: satisfecha su venganza, vuelve a su hogar pero lo encuentra vacío: su mujer ha muerto, víctima del arrepentimiento y los malos tratos del esposo. Primitivo, sin voluntad para luchar, sigue en un estado de embrutecimiento total; un día pone fuego a su casa y muere en medio del incendio.

Tocles y Amabí viven en la ciudad; él entregado a sus lecturas filosóficas y ella a sus pedagogías. Desengaños políticos amargan el carácter del soñador; dificultades de orden moral y económico empiezan a minar la felicidad conyugal. El nacimiento de un hijo, con el consiguiente viaje de Mamagela a la ciudad, viene a cambiar el aspecto de las cosas. Tocles, guiado por los prácticos consejos de su suegra y confiando que en la acción encontrará su paz perdida, decide hacerse estanciero. $Y$ por un tiempo todo marcha bien, pero luego sus lecturas y meditaciones y la conciencia de que sacrifica ideales superiores por dedicarse a la agricultura, le hacen caer en un estado de peligroso aniquilamiento volitivo, enajenándose hasta el cariño de Amabí. Cuando Mamagela le comunica que acaba de ser elegido diputado, Tocles le contesta con una negativa. Prefiere vivir en el miraje de sus utopías, desligado completamente de su medio, ajeno a toda lucha. Ya listo para abandonar a su mujer y a su hijo, ahogada la protesta de sus sentimientós, el profundo afecto y el sentido común de Mamagela le retienen en el hogar. Ahora es diputado y estanciero; su voluntad revive y por fin destruye sus sueños imposibles y sus especulaciones metafísicas quemando los manuscritos de sus obras.

Hay en El terruño dos novelas refundidas. En la de Primitivo, esbozada antes casi en idéntica forma en su cuento primero de Academias, titulado también Primitivo, Reyles usa, 
y abusa del determinismo a la manera de Zola y los Goncourt. Asistimos a la formación de una cultura rural; los dos hermanos representan las dos fuerzas antagónicas de toda sociedad: Jaime, barbarie, anarquía, maldad; Primitivo, progreso, trabajo, honradez, orden y bondad. Después de la traición, Primitivo se convierte en el genio del mal y Celedonia, su mujer, se eleva a una verdadera grandeza en la expiación de su crimen. En el otro relato Tocles es el soñador impráctico, el idealista descentrado, la mente errante, agobiada de lecturas y filosofías extrañas al ambiente; es en resumen, la ciudad, o esa parte de ella que se limita a las academias, a la Universidad y corrillos literarios. Tocles, nutrido de ideas nebulosas y frases vagas pierde contacto con el mundo circundante y su voluntad se atrofia. Del abismo que existe entre su cultura demasiado vasta y su voluntad claudicante surge el conflicto de toda su vida. Mamagela es su antítesis, mujer española que sabe lo que quiere y que al fin logra dominar a Tocles y hacer de él un hombre útil a la sociedad rural en formación.

Junto a este doble estudio psicológico individual y colectivo Reyles nos explica la labor destructora de los partidos políticos en su manera acostumbrada de actuar, la revolución. La revolución arroja sus hordas de ociosos y forajidos sobre los campos indefensos. Los rebeldes se apoderan de los animales y los alimentos; los soldados del gobierno confiscan todos los haberes y arrebatan a los hijos de los brazos de sus madres. Quedan las haciendas abandonadas por falta de brazos; se secan los pastales; desaparecen los ganados, todo queda desierto y solitario. En su carácter de americano culto Reyles anatematiza la revolución pero como artista que es, siente el soplo de pasión de los actos heroicos.

Es por esto por lo que describe con lírico entusiasmo la vida del caudillo Pantaleón y recoge la escena de su muerte en un fresco de intenso colorido y primitivo vigor:

"Por la cicatriz que le partía la cara, el sacristán reconoció a Primitivo. Estremeciéndose de horror, apartó los ojos y los puso luego con ansias mortales en los jinetes que, vociferando, 
perseguían a Pantaleón. Algunos lo denostaban, otros lo habían reconocido y, admirados de su indómito valor, le gritaban que se rindiese; pero él no hacía caso; parando con la lanza, diestramente, las boleadoras que le arrojaban, huía hecho un ovillo sobre el lomo del caballo. De tiempo en tiempo, cuando se veía muy acosado, revolvíase como un toro furioso, y se abría camino dando y recibiendo golpes. En aquellos supremos instantes de sonambulismo heroico, sintiendo las embriagueces del peligro y la locura del matar, sólo pensaba en no caer prisionero, en morir peleando, según la fiera tradición de su raza. La misma sangre caliente que le corría por el rostro y le mojaba los labios, le enardecía como si bebiese un licor de fuego. «iSalvajes! ¡Ladrones! Van a ver cómo muere un criollo!», se decía, viendo sin espanto, al contrario, con exaltación bélica, los grupos de milicos que le salían al encuentro por todas partes. Un tiro de bolas le arrancó la lanza de la mano; no le quedaba arma ningtna; el tordillo daba signos de fatiga; los enemigos lo rodeaban. Entonces Pantaleón, adelantándose a la muerte, tarda en venir, pasó de industria todo el pie a través del estribo, y, golpeándoles la boca en son de burla a sus perseguidores, gritó: « ¡Viva la revolución!» $\mathrm{Y}$ se dejó caer. La soldadesca, espantada, sentó los caballos; hasta los más desalmados sintieron los escalofríos del horror: el cuerpo del caudillo arrastrado en veloz carrera, fué rebotando sobre el suelo hasta quedar convertido en una masa informe". (I)

Reyles ha sido estanciero y sabe lo que significa para la gente de los campos la desatada furia de la revuelta armada. Así lo explica en airada página:

"Era el grito desesperado de los estancieros, víctimas de las agitaciones políticas y los desmanes de las hordas partidarias. Los rurales vivían temblando. Periódicamente, el país entero se agitaba en hondas convulsiones; los gauchos huían a los montes, emigraban del país, después de haber liquidado a vil precio vacas y ovejas, o engrosaban las filas revolucionarias, la mayor

(1),-El terruño, ed. de I927, págs. $273,274$. 
parte de las veces, no por ardiente partidismo, sino para escapar a las levas del Gobierno; la labor nacional se interrumpía; a las efervescencias políticas seguía el tumulto de las armas, y empezaban las incursiones de los bárbaros con divisa blanca o con divisa roja. Los ejércitos, las huestes vandálicas, eran como mangas de langosta que lo asolaban todo: llevábanse los hombres y los caballos, destruían los alambrados, quemaban los montes, diezmaban las haciendas. El respeto de la vida y la propiedad, fundamento y sostén hasta de las más precarias civilizaciones, desaparecía y en un desate de instintos feroces, todo tornaba a la barbarie. Tal era el precipitado de la política nacional, política de sablazos y discursos, grotesca, política de analfabetos y leguleyos. La eterna querella de los partidos tradicionales, o mejor dicho, la lucha de ambos por el poder $y$ la privanza, bien que idealismos ornamentales la disfrazasen, no tenía otra solución que la guerra civil, fruto indigesto del árbol democrático crecido en yermas tierras ideológicas y no disciplinado por la mano dura de la grande razón. Según aseguraban los gerifaltes de la cosa pública en muy peinados y conceptuosos discursos, la guerra era necesaria para salvar los principios, las libertades, los derechos y organizar constitucionalmente la vida de la nación. Entre tanto, empezaban por arruinarla y ponerla en peligro de muerte. Mas, caso peregrino y gracioso: a pesar del trasnochado racionalismo de los doctores y las truculencias caudillescas, el país prosperaba, gracias a que las energías productoras y la evolución de los intereses iban estableciendo las eternas jerarquías y el orden supremo allí donde los políticos ponían sólo farragosa confusión”. ( I)

En Primitivo está esbozado El termño. En el prólogo de su primera Academia se queja Reyles del atraso en que está la novela española, a fines del siglo: "Lo que fué en el gran siglo XVI, costumbrista y picaresca". El quiere dar "un fruto que sea hijo legítimo de su tiempo; una obra de arte que no permanezca indiferente a los estremecimientos e inquietudes

(1) - - Ibid, págs. $97,98,99$. 
de la sensibilidad fin de siglo, tan refinada y compleja". Parafraseando a Goncourt dirá:

"Los que pidan a la obra de imaginación mero solaz, un pasatiempo agradable, el bajo entretenimiento, no me lean. Además no quiero entretener a nadie: pretendo hacer sentir y hacer pensar por medio del libro, lo que puede sentirse en la vida sin grandes dolores, lo que no puede pensarse sino viviendo, sufriendo y quemándose las cejas sobre los áridos libros de los psicólogos de colegio". (I)

Si1 procedimiento es bien sencillo. Siguiendo la fórmula de los realistas franceses, Balzac, Flaubert, los Goncourt, y en parte la de Zola, Reyles desgaja de la vida misma el caso especial y to elabora en estos esbozos. Busca desde luego la representación exacta de la realidad. Del Zola de Rougon-Macquart "histoire naturalle et sociale d'une famille sous le seconde Empire", el novelista uruguayo saca la teoría de que la novela debe ser una demostración. La familia francesa proviene de un matrimonio legal y de un adulterio; una madre neurópata, un marido sano y un amante alcohólico, y los hijos, legítimos y naturales, reflejan las características hereditarias. En la novela de Reyles el padre de Primitivo es un extranjero pacífico y trabajador; la madre, una mujer que se deja engañar y el padre de Jaime es el gaucho malo. "Los cachorros sacan las manchas de sus progenitores", dice Reyles. Primitivo es bueno y honrado, y su hermano, gaucho matrero y alcohólico, le seduce a su mujer. Sin embargo, el método interno que sigue el autor uruguayo, el análisis psicológico ceñido, el deseo de estudiar lo que hay de general en lo individual, le apartan de la idea del "roman expérimental" y le acercan a la concepción de la psicología científica de Paul Bourget, de quien dijo magistralmente Jules Lemaitre: "Cet homme d'aujourd'hui offre une combinaison singulière d'esprit scientifique, de sensualité fine et triste, d'inquiétude morale, de compassion tendre, de religiosité renaissante, de penchant att mysticisme".

(1)-Academias, I, Primitivo, Montevideo, I896, págs. 7, 8, 0. 
El terrñ̃o es una novela de tesis. Quiere demostrar el autor en la actuación de Tocles que para la vida son inútiles las teorías intelectuales, las abstracciones metafísicas y el ensueño y que la suprema satisfacción está en el trabajo y en el esfuerzo utilitario. Lo curioso es que El terruño trae un prólogo de José Enrique Rodó, apóstol del idealismo y de la meditación, del desinterés y del esteticismo, que quería para su continente una cultura que fuera exquisita mezcla de paganismo griego y cristianismo. Claro está que Rodó no quiso ver en el fracaso de Tocles una sátira a la aspiración ideal del hombre sino a la vanidad de la aspiración ideal; y así, explicando mucho más satisfactoriamente a este personaje, escribe:

"Mientras en esos caracteres tiene representación el campo, ya laborioso, ya salvaje, la propensión y la influencia del espíritu urbano encarnan, para el novelista, en la figura de un iluso perseguidor de triunfos oratorios y de lauros proféticos; apóstol en su noviciado, filósofo que tienta su, camino. La especulación nebulosa y estéril; la retórica vacua; la semiciencia hinchada de pedantería, la sensualidad del aplauso y de la fama; el radicalismo quimérico y declamador; todos los vicios de la degeneración de la cultura de universidad y ateneo, arrebatando una cabeza vana, donde porfían la insuficiencia de la facultad y la exorbitancia de la vocación, hallan cifra y compendio en el Tocles de esta fábula. No es necesario observar, en descargo de los que a la ciudad pertenecemos, que Tocles no es toda la ciudad, no es toda la cultura ciudadana, aunque sea la sola parte de ella que el autor ha querido poner en contraste con la vida de campo; pero la verdad individual del personaje, y también su verdad representativa y genérica, en tanto que no aspire a significar sino ciertos niveles medios de la cultura y del carácter, no podrán desconocerse en justicia. Tocles es legión; como lo es, por su parte, el positivista menguado y ratonil, especie con quien la primera se enlaza por una transición nada infrectente ni difícil en la dialéctica de la conducta. De la substancia espiritual de Tocles se alimentan las «idolatrías» de club y de proclama; los fetichismos de la tradición, los fetichismos de la utopía, las heroicas vocaciones de Gatomaquia, la ociosidad de la mala lite- 
ratura. . . ; y del desengaño en que forzosamente paran esos falaces espejismos aliméntanse después, en gran parte, las abdicaciones vergonzosas, las bajas simonías del parasitismo político, común refugio de soñadores fracasados y de voluntades que se han vuelto ineptas para el trabajo viril e independiente". (I)

Lo que pasa es que la personalidad de Tocles no está plenamente lograda en la novela de Reyles. Agréguese a esto que el personaje novelesco y el autor ofrecen extraordinaria similitud y se verá cuánta razón han tenido los críticos adversos a este libro. En efecto, Alberto Zum Felde tiene razón al decir:

"La tesis anti-intelectual de $E l$ terruño es tanto más desconcertante, cuando se sabe que por paradójica ironía mucho de lo que piensa, dice y hace el señor Temístocles Pérez y Gonzáles es... lo que el propio Reyles ha pensado, dicho y hecho. Este es el más sabroso aspecto de El terruño. Academias se llama el cenáculo literario en que Tocles se reúne con sus camaradas de mocedad, evocando, en nombre y carácter, las Academias del autor. El club político que Tocles funda luego, con velada ambición de conquistar posiciones gubernativas, recuerda, en casi todas sus circunstancias, aquella aventura del club Villa Nueva (fundado por Reyles). Más tarde, Tocles repite, como propios, los conceptos principales de La muerte del cisne; y se propone, último de sus vanos empeños quijotescos, construir una Liga Rural, de carácter político-económico, con idéntico programa al anunciado por Reyles en I903, en El ideal nuevo. El terruño es, de cualquier modo que se le interprete, una ironía de doble filo; y el autor se hiere con ella a sí mismo. Ha querido escarnecer al intelectualismo, más aún que en La raza de Cain; allá aún le deja la tragedia; aquí sólo está la burla; pero ¿no se ha escarnecido él mismo también en cierto modo?" (I)

La respuesta en sencilla: o Reyles ha tenido el valor de exponer su propio caso, o sintiéndose superior al ambiente y al

(1).-El terruño, págs. XXII y XXIII.

(2).--Proceso intelectual del Uruguay, tomo II, págs. 286, 287. 
héroe de su novela; ni siquiera ha pensado en su propia dolencia.

Sin entrar en el estudio de las influencias literarias extranjeras que hayan actuado en esta novela, en especial de Stendhal, Bourget, Prévost, Huysmans, d'Annunzio, Tourguenief, Gorki, Dostoiewski, ya observadas por Luisa Luisi (r), quiero apuntar aqui el beneficio que ha reportado a este autor el estudio de los clásicos españoles y de algunos novelistas de fines de siglo como Valera, Pereda y Galdós. Del Quijote no sólo hay puntes de estilo que convendría estudiar, sino también situaciones y episodios análogos. Algo de Don Quijote tiene Tocles y mucho de Sancho la utilitaria y prosaica Mamagela. Los discursos de ésta, al aire libre, rodeada de ovejeros, ya que no cabreros; la matanza de ovejas hecha por Primitivo al resplandor de la hoguera y sobre todo el suceso fenomenal de Papagoyo cuando ataca, lanza en ristre, a un nocturno enemigo que le hiere fieramente en el pecho y que resulta ser un vulgar pollino, atestiguan la profunda admiración que siente Reyles por la obra inmortal y cómo la tuvo presente en su memoria al escribir El terruño.

(Contimuará).

Arturo Torres-Rioseco.

(1).-V. Escritores uruguayos, Carlos Reyles, Nosotros, Año XVI, T. XLI, 1922, págs. 292 y 45 I. 